\title{
ISOLAMENTO E IDENTIFICAÇÃO DE MICRORGANISMOS PRESENTES EM SUPERFÍCIES DE TECLADOS E MOUSES DE UMA UNIVERSIDADE DE TRÊS LAGOAS, MS
}

Matheus Henrique Reis da Silva ${ }^{1}$; Armindo Henrique Barreto Gotardi ${ }^{1}$; Andreia Aparecida Silva de Barros $^{1}$; Rony Carlos Barcelos Blini ${ }^{1}$; Luiz Gustavo Bernardes ${ }^{1}$; Aline Rafaela da Silva Rodrigues Machado $^{2}$; Odanir Garcia Guerra ${ }^{1}$; Alex Martins Machado ${ }^{1}$

${ }^{1}$ Universidade Federal de Mato Grosso do Sul - UFMS/CPTL, ${ }^{2}$ Universidade de São Paulo, Faculdade de Medicina de Ribeirão Preto - FMRP/USP. e-mail: matheush.reis@hotmail.com

\section{RESUMO}

Objetos do cotidiano podem ser importantes veículos para transmissão de microrganismos. Objetivamos estudar a ocorrência de microrganismos em teclados e mouses de computadores de uma instituição ensino superior. Swabs umedecidos com solução salina foram friccionados sob as superfícies dos teclados e mouses e utilizados para semear em meios de cultura específicos para isolamento de bactérias e fungos. Observamos um grande número de bactérias isoladas, principalmente dos gêneros: Staphylococcus ssp, Streptococcus spp, Enterococcus spp, Corynebacterium spp, Klebsiella spp, Escherichia ssp., entre outros bacilos gram negativos. Interessantemente, foram isolados cepas de Gardnerella spp e Legionella spp. Dentre os fungos, observamos 30 espécies de fungos diferentes, principalmente dos gêneros: Absidia $s p$, Acremonium sp, Aspergillus sp, Candida sp, Fusarium sp, Geotrichum sp, Malassezia sp, Microsporum sp, Pinicillum sp, Rhodotorula sp, Trichoderma sp, Trichophyton $s p$ e Tricosporum sp. Deste modo, concluímos que estes objetos podem ser importantes veículos de transmissão de microrganismos para seres humanos.

Palavras-chave: Contaminação bacteriana, Contaminação fúngica, Teclados, Mouse e Computadores.

\section{ISOLATION AND IDENTIFICATION OF MICROORGANISMS IN THESE AREAS KEYBOARDS AND MICE A UNIVERSITY OF TRÊS LAGOAS, MS}

\begin{abstract}
Objects can be important vehicles for the transmission of microorganisms. We aimed to study the occurrence of microorganisms from keyboards and mouse computers of a Education Institution. Swab was rubbed on the surfaces of keyboards and mouse computers and used for isolation in specific culture media of bacteria and fungi. Observed a large number of bacterial isolates, mainly of the genera: Staphylococcus spp, Streptococcus spp, Enterococcus spp, Corynebacterium spp, Escherichia ssp, and others Gram negative bacillus. Interestingly, strains of Gardnerella spp and Legionella spp were isolated from one samples. Among the fungi, we observed 30 different species, mainly of the genera: Absidia sp, Acremonium sp, Aspergillus sp, Candida sp, Fusarium sp, sp Geotrichum, Malassezia spp, Microsporum sp, Pinicillum sp, Rhodotorula sp, Trichoderma sp, Trichophyton sp and Tricosporum sp. Therefore, we conclude that these objects can be important vehicles of transmission of microorganisms for humans.
\end{abstract}

Keywords: Bacterial contamination, Fungal contamination, Keyboards, Mouse and Computers. 


\section{INTRODUÇÃO}

Os microrganismos são de distribuição ubíqua na natureza podendo ser transmitidos de indivíduos infectados para o ambiente e a objetos do cotidiano. O compartilhamento destes objetos e materiais pode facilitar a transmissão interpessoal de microrganismos podendo causar processos infecciosos graves $^{1}$.

Ambientes como interior de ônibus, e objetos como dinheiro, celulares, telefones públicos, copos ou xícaras de bares e restaurantes, entre outros, são fontes e veículos de microrganismos patogênicos ao ser humano, pois podem ser utilizados por grande número de indivíduos, em um curto prazo de tempo ${ }^{2-4}$.

A contaminação de superfícies em ambiente doméstico demonstra que todos os ambientes estão suscetíveis a contaminação de microrganismos, estando relacionados com a higiene do local. Sendo assim, objetos que estão em contato com várias pessoas podem possibilitar a contaminação de superfícies e causar infecções em organismos debilitados. Assim, observa-se uma intrínseca ligação entre infecções e superfícies contaminadas, sendo a contaminação das mãos o veículo de transferência de microrganismos de objetos para o interior do organismo ${ }^{5}$.

Dentro deste âmbito, ainda que não relatado na literatura, teclados e mouses de computadores podem ser fontes de grande número de microrganismos, muitos deles patogênicos ao homem. Estes microrganismos podem ser veiculados pelas mãos e entrarem em contato com a pele e/ou mucosas, principalmente ocular e oral, podendo causar sérios processos infecciosos ${ }^{6}$.

A presença de determinados microrganismos nestes objetos podem estar relacionadas a condições higiênico-sanitárias insatisfatórias, e/ou ao uso coletivo destes objetos. Desta forma, o objetivo do presente trabalho foi realizar estudo sobre o perfil microbiológico isolado a partir de teclados e mouses utilizados por profissionais e acadêmicos da Universidade Federal do Mato Grosso do Sul, campus Três Lagoas/MS (UFMS-CPTL).

\section{METODOLOGIA}

Coleta e processamento das amostras

Foram coletadas amostras dos computadores da UFMS-CPTL, localizados nos laboratórios de Informática e Pesquisa/Ensino, bem como os computadores de pesquisa da biblioteca universitária e de professores. Para isto, swabs estéreis umedecidos com solução salina foram friccionados sobre a superfície do teclado e mouse, identificados e utilizados para semeadura em meio de cultura Miller Hinton (MH) e Agar Sabouraud Dextrose 
(SDA), para identificação de bactérias e fungos respectivamente. Após crescimento as colônias bacterianas foram isoladas em novos meios de cultura $\mathrm{MH}$, e as colônias de fungos repicadas em SDA.

Identificação das bactérias e fungos

As colônias bacterianas obtidas foram submetidas à coloração de Gram, sendo às com aspecto Gram-negativo, submetidas a provas bioquímicas para identificação. Para identificação dos cocos Gram-positivos foram realizados testes de catalase, plasma coagulase e sensibilidade a novobiocina ${ }^{7}$.

As colônias leveduriformes subcultivadas em ágar SDA foram inicialmente identificadas com base em sua morfologia e prova de produção de tubo germinativo, produção de clamidoconídio em ágar fubá contendo Tween 80 e provas de assimilação em fontes de carbono e nitrogênio e fermentação.
A identificação dos fungos filamentosos foi baseada na técnica de micro cultivo em ágar-batata dextrose aliado a observação da morfologia macroscópica das colônias ${ }^{8}$.

\section{RESULTADOS}

Foram analisados 30 diferentes computadores, obtendo 30 amostras de teclado e 30 amostras de "Mouse" para fungos e bactérias respectivamente, totalizando 120 amostras analisadas. Destas, $96,6 \%$ apresentaram isolamento de microrganismos, sendo encontrados principalmente os gêneros: Staphylococcus ssp, Streptococcus spp, Enterococcus ssp, Bacillus spp, Corynebacterium spp, Klebsiella spp, Proteus spp, Neisseria spp, Klebsiella spp, e Escherichia coli além de outros bacilos Gram Negativos. 


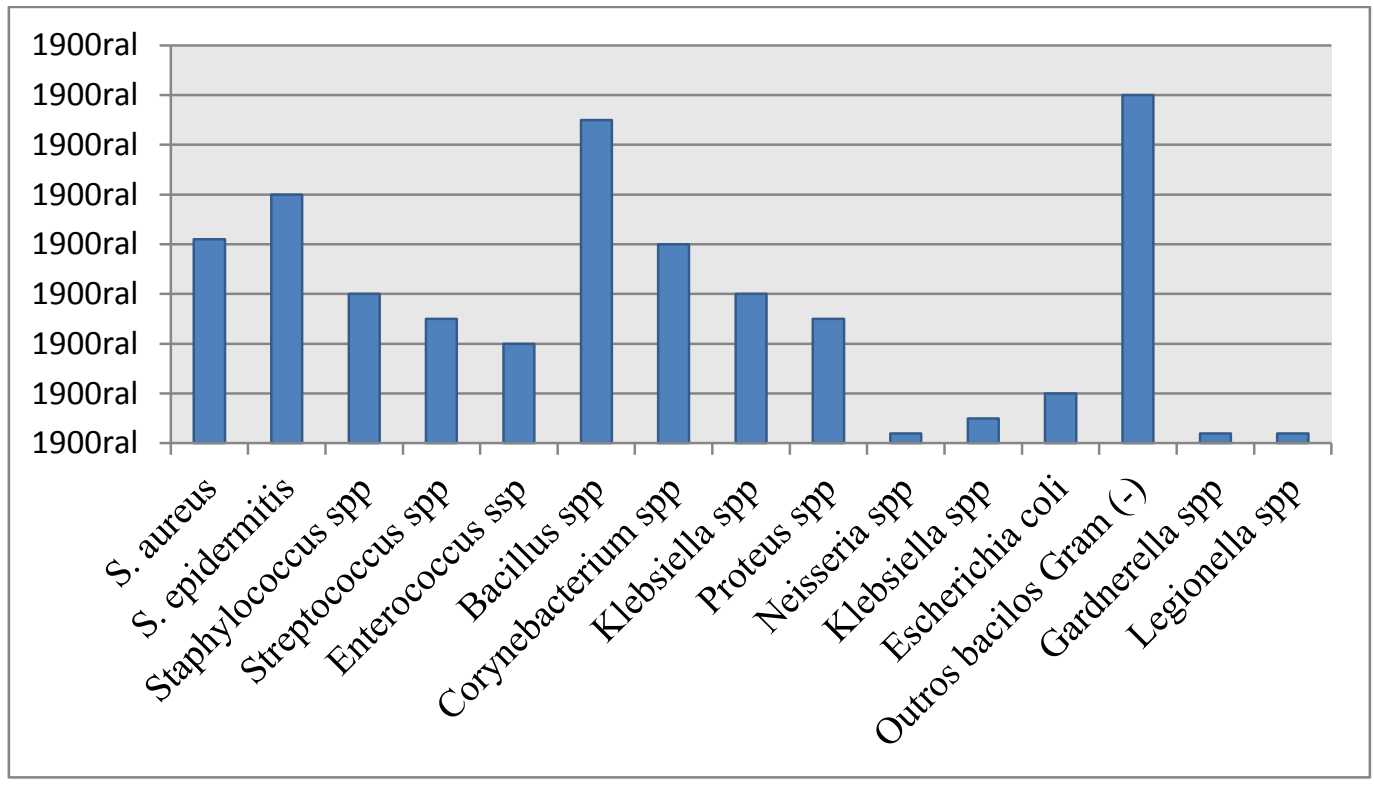

Figura 1. Porcentagem de computadores positivos ao isolamento de diferentes gêneros bacterianos.

Analisando os fungos encontrados, observamos que os gêneros de fungos mais encontrados foram: Absidia sp, Acremonium $s p$, Aspergillus sp, Candida sp, Fusarium sp,
Geotrichum sp, Malassezia sp, Microsporum sp, Pinicillum sp, Rhodotorula sp, Trichoderma sp, Trichophyton sp e Tricosporum sp (Figura 2)

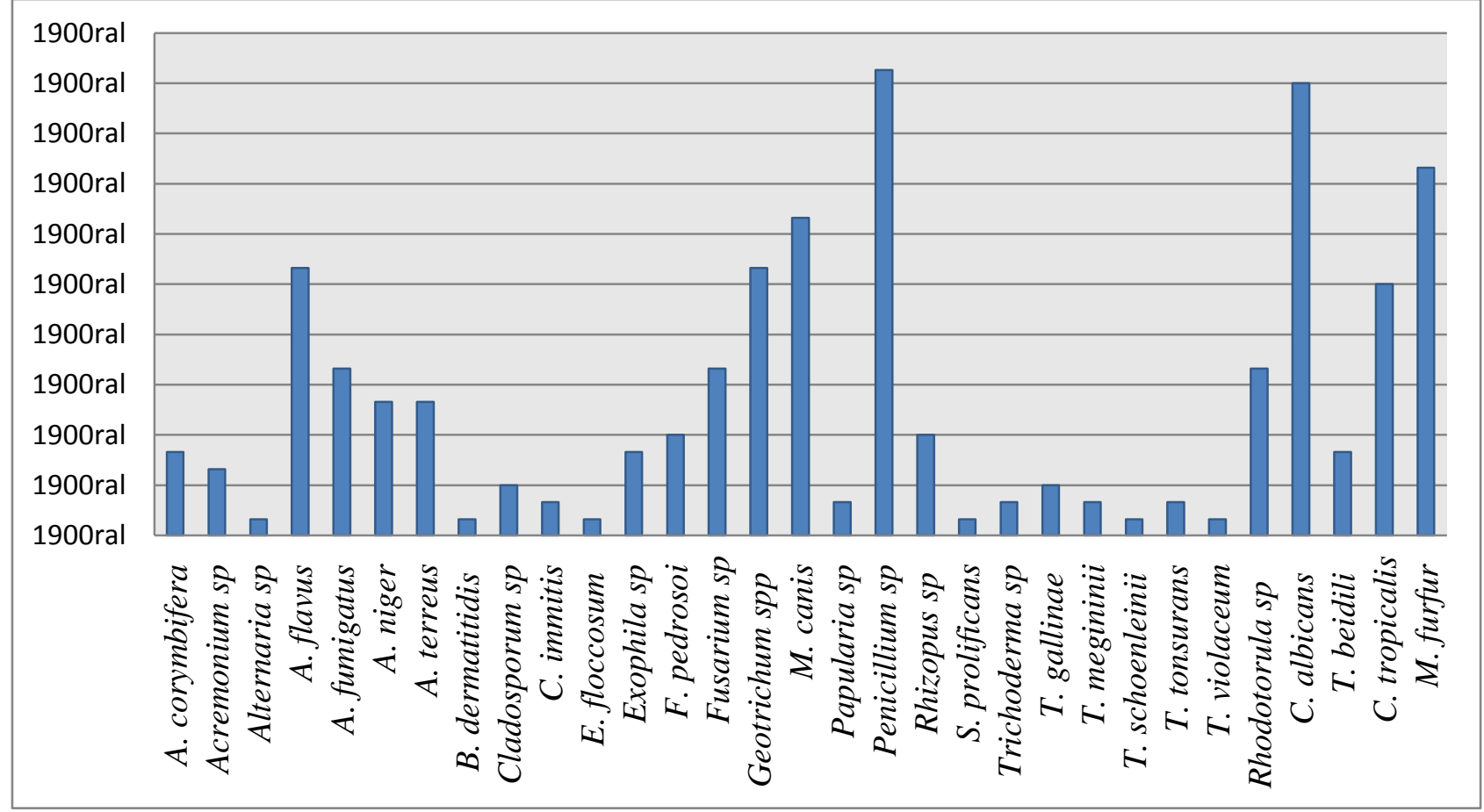

Figura 2. Porcentagem de computadores positivos ao isolamento de diferentes espécies de fungos. 


\section{DISCUSSÕES}

A sobrevivência de microrganismos em fômites é um importante fator para se avaliar o potencial de exposição a que estão submetidas às pessoas que frequentam um determinado ambiente. Certos microrganismos, que são infecciosos em quantidades relativamente pequenas, podem ser isolados depois de prolongados períodos de sobrevivência sobre superfícies inanimadas, como telefones, maçanetas e demais objetos $^{9-10}$.

No presente estudo obtivemos 60 amostras de computadores (Teclado e Mouse) com 96,6\% destas contaminadas por bactérias de diferentes gêneros: Staphylococcus ssp, Streptococcus spp, Enterococcus ssp, Bacillus spp, Corynebacterium spp, Klebsiella spp, Proteus spp, Neisseria spp, Klebsiella spp, e Escherichia coli além de outros bacilos Gram Negativos.

Uma pesquisa da mesma natureza, realizada por Bures et al. ${ }^{11}$, em amostras de 80 teclados de computadores, mostrou que $24 \%$ estavam contaminadas por microrganismos, principalmente dos gêneros Staphylococcus; Enterococcus; Enterobacter e por bastonetes Gram-negativos.

Anderson et $a l^{6}{ }^{6}$, em pesquisa semelhante realizada em teclados de computadores de três laboratórios de informática do campus de Swinburne, da
Universidade de Tecnologia de Melbourne (Austrália), estavam predominantemente contaminados por Staphylococcus aureus e enterobactérias, sendo que Enterococcus faecallis colonizava todos os teclados.

Observamos grande semelhança destes estudos, com o realizado em nossa instituição. $\mathrm{Na}$ nossa pesquisa os computadores de uso coletivo (Laboratório de Informática e/ou Ensino e biblioteca) foram os que apresentaram uma maior diversidade microbiana, assim como um maior número de espécies potencialmente patogénicas, em comparação com as os computadores de trabalho usado por predominantemente uma ou duas pessoas.

Assim computadores utilizados por somente uma pessoa, mostrou números de isolados significativamente menores, sendo que um destes computadores não mostrou nenhum tipo de contaminação bacteriana ou fúngica, o qual pode ser explicado devido a que o mesmo era de uso restrito a um só funcionário e com poucos dias de uso.

Analisando as espécies de microrganismos isolados neste estudo, muitos pertencem à microbiota humana ou são encontrados no meio ambiente, como exemplo as bactérias dos gêneros Staphylococcus e Corynebacterium que predominam na pele de humanos ${ }^{12-13}$. Entretanto, algumas considerações a respeito do potencial patogênico desses 
microrganismos merecem ser descritos. Assim, uma espécie de estafilococos, o Staphylococcus aureus, pode causar diferentes processos infecciosos, quando em contato com mucosas, sendo potenciais causadores de infecções de maior gravidade em portadores de outras doenças infecciosas, e ou em indivíduos que estejam com seu sistema imunológico comprometido. Outro estafilococo encontrado, o $S$. epidermidis o qual pertence à microbiota da pele humana, narinas, boca, uretra e em menor quantidade na conjuntiva, faringe, intestino e vagina e considerado uma bactéria comensal, possui grande potencial patogênico a quando adquiridos por indivíduos imunocomprometidos ${ }^{13}$.

Outros gêneros de importância clínica, isolado nestas amostras, foi o Enterococcus spp e Klebsiella spp, os quais possuem espécies causadores de importantes infecções em animais e seres humanos ${ }^{14}$.

Devido a sua importância médica as enterobactérias são um dos mais bem definidos e estudados grupos de bactérias Gram-negativas. Neste trabalho isolamos três gêneros pertencentes a este grupo: Klebsiella spp, Proteus spp, Escherichia spp. Todos estes microrganismos pertencem à microbiota humana, no entanto podem causar importantes infecções do trato gastrointestinal $^{13}$.
Interessantemente em um dos computadores analisados, foi isoladas cepas de Gardnerella spp. que pertence à microbiota vaginal e também cepas de Legionella spp que podem causar infecções pulmonares.

Estudos relacionados ao isolamento de fungos de teclados e mouses são escassos na literatura, restringindo-se há apenas a presença ou ausência e se filamentoso ou leveduriforme, sem a descrição do gênero e/ou espécie encontrado.

Observamos em nosso trabalho uma grande diversidade de fungos isolados de computadores, e semelhantemente ao observado com as bactérias a maior diversidade de fungos foram isoladas nos computadores compartilhados pelos universitários.

Sobre os fungos isolados, eles podem ser agentes etiológicos de zigomicose (Absidia sp, Mucor sp), otomicose (Mucor sp, Aspergillus sp, Penicillium sp), ceratomicose (Absidia sp, Bipolaris sp). Além de estarem associados a outras doenças, que podem ser transmitidas por elementos fúngicos ou seus produtos metabólicos, entre estas destacamos as alergias, tóxicas ou infecciosas (micoses). As micoses são as doenças fúngicas mais representativas, normalmente são causadas por fungos oportunistas e podem ser classificadas em superficiais, cutâneas e sistêmicas. Entre os causadores 
de micoses superficiais e cutâneas nós isolamos fungos dos gêneros: Candida $s p$, Malassezia sp, Cladosporum sp, Tricosporum $s p$, Trichophyton sp, Sporothrix schenckii, Exophiala $s p, \quad$ Geotrichum $s p$, Epidermophitom sp, Microsporum sp e Fusarium sp. No presente estudo não foi isolados fungos causadores de micoses sistêmicas ${ }^{13}$.

Outro fungo de importância clínica, isolado em nossas amostras, foi o Aspergillus $s p$, sendo que as espécies que compreende este gênero são extremamente comuns no meio, porém podem estar associados à doença invasiva, principalmente pulmonar em indivíduos imunocomprometidos ${ }^{8}$. 0 gênero Fonsecaea sp. também isolado neste trabalho, também se caracteriza como um agente oportunista, podendo levar a infecções oculares ${ }^{5}$.

Assim Anderson e Palombo ${ }^{6}$ e Hartmann et al. ${ }^{15}$, afirmam que os teclados dos computadores podem ser um grande propagador de microrganismos causadores de doenças infecciosas, e os resultados desta pesquisa deixam evidente a necessidade de realização de um trabalho educativo junto à sociedade universitária, reforçando os bons hábitos higiênico-sanitários e evitando a contaminação, proporcionando assim, um ambiente livre de microrganismos causadores de inúmeras doenças.

\section{CONCLUSÃO}

Diante dos resultados obtidos neste estudo, conclui-se que a maioria dos computadores estavam contaminados com bactérias e com fungos, sendo isolados mais de 30 espécies diferentes de fungos e 9 de bactérias, sendo a maioria destes microrganismos pertencem ao ambiente ou a microbiota humano, e alguns potencialmente patogênicos.

O presente estudo fortalece a premissa de que tais microrganismos estão ligados a falta de higiene das mãos e que investimentos em educação higiênicosanitária para a comunidade universitária são altamente recomendados.

Outrossim os dados deste estudo, pioneiro no município de Três Lagoas, MS e provavelmente no Estado de Mato Grosso do Sul, dada a escassez de literatura especializada, contribuem para o conhecimento do grau e do tipo de contaminação microbiana encontrada em teclados e mouses, e também alerta para a necessidade de outros estudos de verificação de contaminação ambiental e de fômites como prováveis veículos de transmissão de doenças.

\section{REFERÊNCIAS}

1. Smith SI. Antibiotic susceptibility pattern of Staphylococcus species isolated from telephone receivers. Singapore Med J. 2009;2(50):208-211. 
2. Hardoim EL, Silva CB, Cunha Neto A. Inquérito Bacteriológico (Enterobacteriaceae) em copos e xícaras de bares e lanchonetes em Cuiabá, Mato Grosso. Cadernos de Saúde. 2000;1: 44-59.

3. Souza AC, Oliveira GEM, Ogawa WN, Poletto KQ. Microrganismos Encontrados em Dinheiro Brasileiro Coletado em Feira Livre. NewsLab, 2006;77.

4. Murta FL, Massara CL. Presença de ovos de helmintos intestinais em ônibus de transporte público em Belo Horizonte-Minas Gerais, Brasil. Rev Patol Tropical. 2009;38(3): 207-212.

5. Bonato BS, Castro FF, Helena RPG. Oculares de microscópios podem ser veículos de contaminação? NewsLab. 2007;81.

6. Anderson G, Palombo EA. Microbial contamination of computer keyboards in a university setting. Am J Infect Control. 2009;37:507-509.

7. Murray PR, Baron EJ, Pfaller MA, Tenover FC, Yolken RH. Manual of clinical microbiology. 7th ed. Washington: ASM Press, 1999.

8. Lacaz CS, Porto E, Heins-Vaccari EM, Melo NT. Guia para identificação: fungos, actinomicetos, algas de interesse médico. São Paulo: Sarvier, 1998.

9. Noskin GA, Stosor V, Cooper I, Peterson LR. Recovery of vancomycin-resistant enterococci on fingertips and environmental surfaces. Infect Control Hosp Epidemiol. 1995;16(10):577-581.

10. Barker J, Stevens D, Bloomfield SF. Spread and prevention of some common viral infections in community facilities and domestic homes. J Applied Microbiol. 2001;91(1):7-21.
11. Bures S, Fishbain JT, Uyehara CFT, Parker JM, Berg BW. Computer keyboards and faucet handles as reservoirs of nosocomial pathogens in the intensive care unit. Am J Infect Control. 2000;28:6:465-471.

12. Ciragil P, Gul M, Aral $M$. Bacterial contamination of computers and telephones in a university hospital in Turkey. J Hosp Infect. 2006;62(2):247-248.

13. Trabulsi LR, Alterthum F. Microbiologia. 5. ed. São Paulo: Atheneu, 2008.

14. Almeida RCC, Kuaye AY, Serrano AM, Almeida PF. Avaliação e controle da qualidade microbiológica de mãos de manipuladores de alimentos. Rev Saúde Pública. 1995;29(4):209-214.

15. Hartmann $B$, Benson $M$, Junger $A$, Quinzio L, Fengler B, Wille B, Hempelmann G, Farber UW, Rohrig R. Computer keyboard and mouse as a reservoir of pathogens in an intensive care unit. J Clin Monit Comp. 2004; 18:7-12.

Recebido para publicação em 18/08/2014

Revisado em 21/08/2014

Aceito em 26/08/2014 